\title{
THEORETICAL STUDIES OF THE HEATING SYSTEM IN THE VEHICLE COMPARTMENT DURING PASSENGER TRANSPORTATION TAKING INTO ACCOUNT BREATHING UNDER CONDITIONS OF LOW TEMPERATURES
}

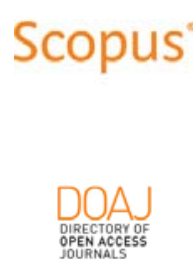

\section{Denis Sergeevich Aleshkov}

Siberian State Automobile and Highway University (SibADI), Department "Technosphere and Environmental Safety", Omsk, Russian Federation

\section{Irina Vladimirovna}

Pogulyaeva

Siberian State Automobile and Highway University (SibADI),

Department "Logistics",

Omsk, Russian Federation
Mikhail Viktorovich Banket

Siberian State Automobile and Highway University (SibADI), Department "Operation and Repair of Automobiles",

Omsk, Russian Federation

Svetlana Vladimirovna Yanchij

Omsk State Technical University (OmSTU) FSBEl of Higher Education, Department "Industrial Ecology and Safety", Omsk, Russian Federation

\section{Mikhail Vladimirovich} Sukovin

Siberian State Automobile and Highway University (SibADI), Department "Technosphere and Environmental Safety", Omsk, Russian Federation

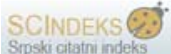

Key words: heating system, microclimate parameters, thermal comfort doi:10.5937/jaes18-27264

\section{Cite article:}

Aleshkov, S. D., Banket, V. M., Sukovin V. M., Pogulyaeva V. I., \& Yanchij, V. S. [2020]. Theoretical studies of the heating system in the vehicle compartment during passenger transportation taking into account breathing under conditions of low temperatures. Journal of Applied Engineering Science, 18(3) 346 - 354. 


\title{
THEORETICAL STUDIES OF THE HEATING SYSTEM IN THE VEHICLE COMPARTMENT DURING PASSENGER TRANSPORTATION TAKING INTO ACCOUNT BREATHING UNDER CONDITIONS OF LOW TEMPERATURES
}

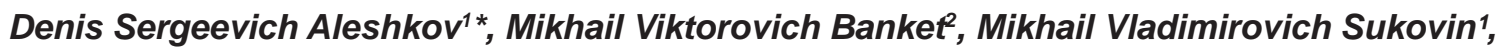 \\ Irina Vladimirovna Pogulyaeva ${ }^{3}$, Svetlana Vladimirovna Yanchij ${ }^{4}$
}

${ }^{1}$ Siberian State Automobile and Highway University (SibADI), Department "Technosphere and Environmental Safety", Omsk, Russian Federation

${ }^{2}$ Siberian State Automobile and Highway University (SibADI), Department "Operation and Repair of Automobiles", Omsk, Russian Federation

${ }^{3}$ Siberian State Automobile and Highway University (SibADI), Department "Logistics", Omsk, Russia ${ }^{4}$ Omsk State Technical University (OmSTU) FSBEl of Higher Education, Department "Industrial Ecology and Safety", Omsk, Russian Federation

This paper presents the results of theoretical computer-aided research of the microclimate parameters in the vehicle passenger compartment during operation of one of the widely used schemes of heating system in the passenger compartment, taking into account the breathing of passengers. Theoretical researches of the heating system operation in the passenger compartment taking into account passenger breathing have been conducted. Distribution of microclimate parameters in the passenger compartment cross-section, in the case of using a heating system having one compartment heater, with and without taking into account the breathing of passengers, has been obtained. The assessment of the effect of passengers' breathing on the microclimate parameters in the passenger compartment has been carried out. The outcomes of this research may be of interest to specialists involved in the design and ergonomics of wheeled vehicles and labor protection.

Key words: heating system, microclimate parameters, thermal comfort

\section{INTRODUCTION}

Transportation of employees to the production site and back can reach 2 hours, which is about $30 \%$ of working time and, accordingly, the microclimate of the passenger compartment has a direct impact on the health of the employee and his subsequent ability to work, as described in methodology [1] and paper [2]. Thus, in the conditions of Arctic exploration, the issue of ensuring permissible and optimal microclimate parameters in the vehicle passenger compartment is a priority, especially during the cold period of the year.

The "passenger - vehicle passenger compartment" system represents a complex thermodynamic system. During breathing, the vehicle passenger, together with the exhaled air, releases heat into the surrounding space. It is of practical interest to estimate the degree of influence of this mechanism of heat exchange on the qualitative distribution of the main microclimate parameters in the passenger compartment.

Researches of human thermal comfort are quite extensive. They cover various elements of the technosphere, such as ventilated accommodation facilities, according to monographs [3, 4], isolated rooms of healthcare facilities, according to paper [5], passenger coaches, according to papers $[6,7]$, passenger compartments of airplanes, according to paper [8], buses, according to paper [9] and cars, as described in papers [10,11, and 12], as well as peculiarities of microclimate parameters distribution in different positions and postures of a person in space resulting from the specificity of his activity and constructive solutions of confined areas described in papers $[5,7]$. It should be noted that studies of microclimate in confined areas are developed in several directions.

Experimental studies with the use of a thermal passenger manikin with the increase of its adequacy presented in papers $[3,6,13,14,17]$ as well as experimental studies of microclimate parameters of the existing systems of thermal comfort provision in passenger compartments of cars [16, 17] and buses [15], including the use of a fullsize climatic chamber described in paper [25] have been conducted. The results of experimental studies of microclimate parameters and atmospheric composition of the passenger compartment for different models of wheeled vehicles in hot climate conditions are presented in papers $[10,18]$. The results of experiments on the assessment of the system operation of thermal comfort provision taking into account the creation of natural ventilation in the passenger compartment under high ambient temperatures are presented in paper [19]. The works devoted to experimental studies of the passenger compartment heating system of the wheeled vehicle under the effect of low temperatures include the paper [20]. However, the number of such studies is significantly less in compari- 
son with the studies in the area of investigating high-temperature exposure. One of the tasks that are solved by experimental studies of thermal comfort regulation in the passenger compartment is to determine the actual values of the initial and boundary conditions of mathematical models for their further computer-based numerical solution, taking into account the subjective perception of microclimate parameters by humans, as is proven in paper [21]. Researches [20, 22, 23, 24, 34] involve the study of functioning thermoregulation mechanisms of the human body and its reaction to the heating and cooling microclimate, such as the model of thermoregulation developed in The University of California, Berkeley (UCB) and the multisegmental (MS) Pierce model, as well as in the compartment of the wheeled vehicle, according to papers $[25,26]$. The purpose of these studies is to improve methodologies for objective evaluation of subjective perceptions caused by the effect of working microclimate parameters. The paper [26] describes the most currently known methods of thermal comfort assessment. The development of microclimate regulation systems is presented in papers [8, 21, 27, 28], and the assessment of their performance by such indicators as energy consumption, thermal comfort and air quality is presented in papers [6, 12, 13, 29, 30, 31, 32, 33].

Theoretical studies of microclimate regulation systems and microclimate effect on humans are based on computer models described in papers $[3,5,7,9,10,25,27$, $28,29,33]$. The papers $[35,36]$ provide a comparative analysis and assessment of the possibilities of various implementations of mathematical models of gas thermodynamics on computers. ANSYS Fluent software suite described in the user's manual [37] should be considered as the most known software product which allows for the assessment of microclimate parameters.

The increase in accuracy of the thermodynamic model implementations on the computer is provided due to the congruence of 3D models, the use of advanced computational algorithms and taking into account all participants in the heat balance creation, according to papers [31, 33, 38]. Thus, accounting for friction and aerodynamic forces in providing thermal comfort is discussed in paper [32], and the role of solar radiation and radiation of the interior panels is discussed in papers [11, 27, 31]. In paper [39] a description of the main parameters of the microclimate in the car compartment and the factors inherent to passengers are presented. However, the author does not explicitly point to such a factor as the change in the gas composition due, inter alia, to the breathing of passengers, which is a constituent element of mass equations of the thermodynamics of wheeled vehicle passenger compartment, according to paper [30]. In paper [40] the analysis of parameters, characterizing the state of thermal comfort, which can be simulated in the bus cabins is presented, and the relevance of more in-depth studies particularly of the passenger compartment of the bus is indicated.

The papers [41, 42] provide a theoretical assessment of the quantitative change of gas composition in the compartment of a wheeled vehicle depending on time and number of passengers. The research trend of human external respiration is developed from the point of view of chemical compounds distribution in the human breathing zone and penetration of the substances into his body, or from the point of view of a human being as a source of external environment pollution, according to papers [43, 44, 45].

Thus, for the moment researches of the effect of practically all elements of the wheeled vehicle technical system on the achievement of thermal comfort in the compartment have been conducted, as can be seen from papers [31, 32, 46]. The assessment of arising subjective sensations of passengers under certain microclimatic conditions is presented in papers $[7,17,26]$. Different schemes of microclimate regulation and thermal comfort provision for different types of wheeled vehicles have been studied in papers [9, 20, 29].

Assessment of changes in microclimate parameters in time and various driving conditions of a wheeled vehicle has been performed in papers [11, 15, 16, 19]. It has been established that the parameters of microclimate in the compartment during movement are not constant, as well as subjective sensations of thermal comfort are different when the vehicle is moving and when it is motionless, as demonstrated in papers [11, 16, 17]. However, almost all papers consider the thermal comfort provision in conditions of heating microclimate which can be found in papers [9, 10, 12, 15, 17, 18, 19, 25, 27, 29, 31, 33]; at the same time passengers represent passive receptors in the context of the environment, as is proven in paper [43]. Therefore, assessment of heating system efficiency under conditions of cooling microclimate in the cold period of the year and determination of actual values of microclimate parameters in the compartment for wheeled vehicles of M3 category with the seating capacity not exceeding 22 passengers, taking into account the external respiration of a person as a constituent element in providing thermal comfort, is one of the further research trends in regulation of microclimate of the passenger compartment of the wheeled vehicle.

The main purpose of this study was to determine the quantitative values of microclimate parameters in the passenger compartment, taking into account the variable boundary conditions simulating the passenger's breathing.

In order to achieve this goal, the following objectives had to be achieved:

- Construction of the calculation model of the passenger compartment of the wheeled vehicle of M3 category with the seating capacity not exceeding 22 passengers;

- Development of a mathematical model of the microclimate formation in the passenger compartment, taking into account the breathing of passengers;

- Computer-based numerical solution and obtaining 
quantitative values of microclimate parameters in the passenger compartment.

\section{THEORETICAL CONSIDERATION}

Let us consider a wheeled vehicle of category M3 with the seating capacity not exceeding 22 passengers (Figure 1). This type of the vehicle is widely used for the transportation of passengers on urban and suburban routes.

Theoretical research of dynamics of a working microclimate and heating system operation, taking into account

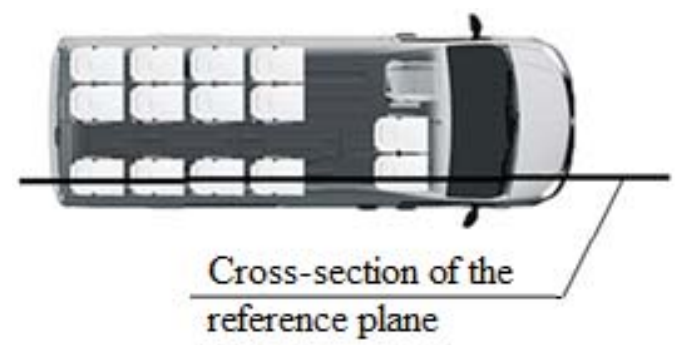

Figure 1: Layout diagram of the wheeled vehicle passenger compartment of M3 category with the seating capacity not exceeding 22 passengers and location of the cross-section of the reference plane breathing of passengers will be carried out on two-dimensional model in the reference plane presented in Figure 1.

The geometric model of the wheeled vehicle passenger

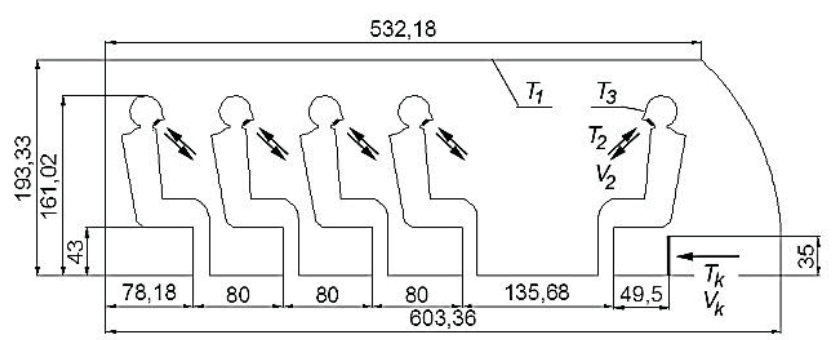

Figure 2: Geometric model of the wheeled vehicle passenger compartment of M3 category with the seating capacity not exceeding 22 passengers

compartment of M3 category with the seating capacity not exceeding 22 passengers is presented in Figure 2. All measurements are in centimeters. The projected area in the passenger compartment was $85853.0099 \mathrm{~cm}^{2}$.

The computational scheme is presented in Figure 2.

The following assumptions were made in the development of the computational scheme:

- The temperature of the passenger compartment wall $\mathrm{T} 1$ is constant;

- The temperature of passenger external integuments T2 is constant;

- Concentrations of organic compounds and CO2 as well as other organic compounds, which affect the air characteristics in the passenger compartment, are ignored;
- The temperature of air exhaled by passengers is constant;

- The temperature $T_{k}$, and speed Vk of the movement of air supplied to the compartment by the heating system of the wheeled vehicle of M3 category with the seating capacity not exceeding 22 passengers is constant;

- The speed $\mathrm{V}_{\mathrm{k}}$, of the air supplied to the passenger compartment by the wheeled vehicle heating system is directed horizontally;

- The boundaries (surfaces) of solid bodies are absolutely smooth;

- All passengers are in the sitting position;

- All passengers are breathing synchronously;

- The duration of inhalation is equal to the duration of exhalation;

- The air speed on inhalation is equal in absolute value to the air speed on exhalation V2.

- The process of inhalation-exhalation was described by the law of air speed change on inhalation and exhalation V2 depending on time t:

$\mathrm{V} 2=\mathrm{a} \cdot \cos (\mathrm{b} \cdot \mathrm{t})$

where $a$ and $b$ are the proportionality coefficients.

The following parameters were accepted as boundary conditions:

- The temperature of the walls of the vehicle passenger compartment was taken equal to $\mathrm{T} 1=253 \mathrm{~K}$ which, according to the CR 131.13330.2012, corresponds to the air temperature with reliability equal to 0.94 for the cities of Krasnoyarsk, Magadan, some settlements of the Komi Republic, as well as accepted with certain assumptions for Omsk and Novosibirsk;

- The temperature of passenger's external integuments based on investigations [7, 9] and taking into account data of the paper [49], amounted to $\mathrm{T} 3=305 \mathrm{~K}$;

- $\quad$ The temperature of air exhaled by passengers was equal to $306 \mathrm{~K}$;

- The sizes of external border of inhalation and exhalation of passenger had the sizes corresponding to the diameter of the circle equal to $0,013 \mathrm{~m}$ that corresponded to the equivalent area of $0,0028 \mathrm{~m}^{2}$ through which inhalation and exhalation were carried out, according to investigations [45, 48];

- In the outlet section of the heater the air temperature Tk was assumed to be equal to $328 \mathrm{~K}$, according to investigation [50];

- The air speed in the outlet section of the heater was $2.88 \mathrm{~m} / \mathrm{s}$, with the value of the heater capacity equal to $250 \mathrm{~m}^{3} / \mathrm{h}$, as shown in investigation [50];

- The total heat flow through the surface of the passenger's skin was $85 \mathrm{~W}$, which corresponds to the working sitting position and the body surface area 
Table 1: Characteristics of materials

\begin{tabular}{|l|c|c|c|}
\hline $\begin{array}{l}\text { Element under } \\
\text { Consideration }\end{array}$ & $\begin{array}{l}\text { Density, } \\
\mathrm{kg} / \mathrm{m}^{3}\end{array}$ & $\begin{array}{l}\text { Specific Heat } \\
\text { Capacity, } \\
\mathrm{J} /(\mathrm{kg} \cdot \mathrm{K})\end{array}$ & $\begin{array}{l}\text { Heat Transfer } \\
\text { Coefficient, } \\
\mathrm{W} / \mathrm{m}^{2} \mathrm{~K}\end{array}$ \\
\hline $\begin{array}{l}\text { Wheeled } \\
\text { vehicle body }\end{array}$ & 2719 & 871 & 202,4 \\
\hline $\begin{array}{l}\text { Passenger } \\
\text { compartment } \\
\text { seats }\end{array}$ & 70 & 1685.6 & 0.05 \\
\hline Skin integument & 1000 & 3770 & 0,21 \\
\hline Clothing & 110 & 1480 & 0,04 \\
\hline
\end{tabular}

equal to $1.5 \mathrm{~m}^{2}$, according to paper [48].

Characteristics of materials used in the simulation are presented in Table 1 which was compiled based on data of papers [31, 45, 48].

The calculation of microclimate parameters in the considered cross-section of the vehicle compartment was performed in ANSYS Fluent software suit. The mathematical model took into account the energy exchange and used the standard $k-\varepsilon$ turbulence model described in papers $[25,29,33]$.

Breathing was simulated in ANSYS Fluent using the UDF function, according to the ANSYS Fluent user's manual [37]. The breathing process was defined by the harmonic function (1). The values of proportionality coefficients were taken into account according to studies $[45,47,48]$ with consideration to the correspondence of breathing frequency equal to $14.26 \mathrm{~min}^{-1}$, which corresponds to the duration of one breathing cycle of $4.2 \mathrm{~s}$ and air flow rate equal to $1.368 \cdot 10-5 \mathrm{~m}^{3} / \mathrm{s}$ [45] with the maximum value of exhaled and inhaled air speed from 2.0 to $2.3 \mathrm{~m} / \mathrm{s}$, according to papers $[45,48]$. Then, taking into account the accepted assumption, duration of inhalation and exhalation is $t=2.1 \mathrm{~s}$. Accordingly, the expression (1) has the next form:

$\mathrm{V} 2=2 \cdot \cos (1,57 \cdot \mathrm{t})$

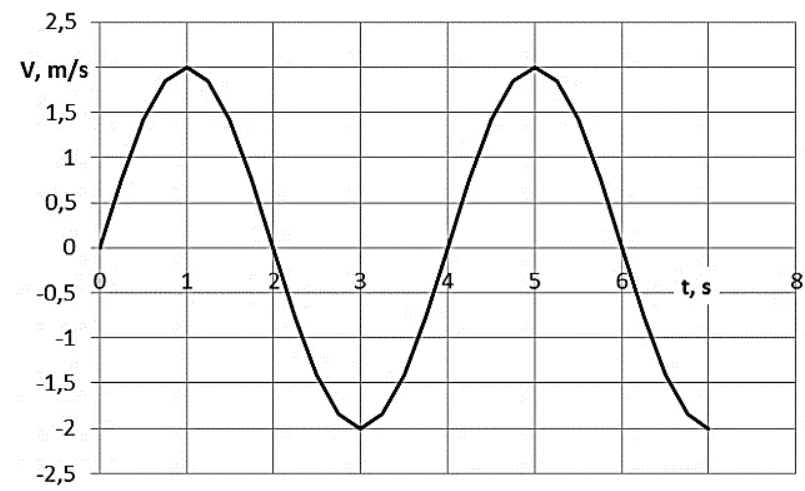

Figure 3: Dependence of air speed on inhalation/exhalation time

Figure 3 represents a graph of air speed change on inhalation and exhalation, depending on time, where the exhalation corresponds to negative values of speed value.
In order to study the effect of passengers' breathing on the process of thermal comfort formation, calculations of microclimate parameters in the compartment of a wheeled vehicle were performed with and without taking into account breathing.

Figures 4, 5, 6 and 7 represent the results of calculations of air temperature parameters, air speed vector, absolute pressure and a fragment of airflow line vectors in the

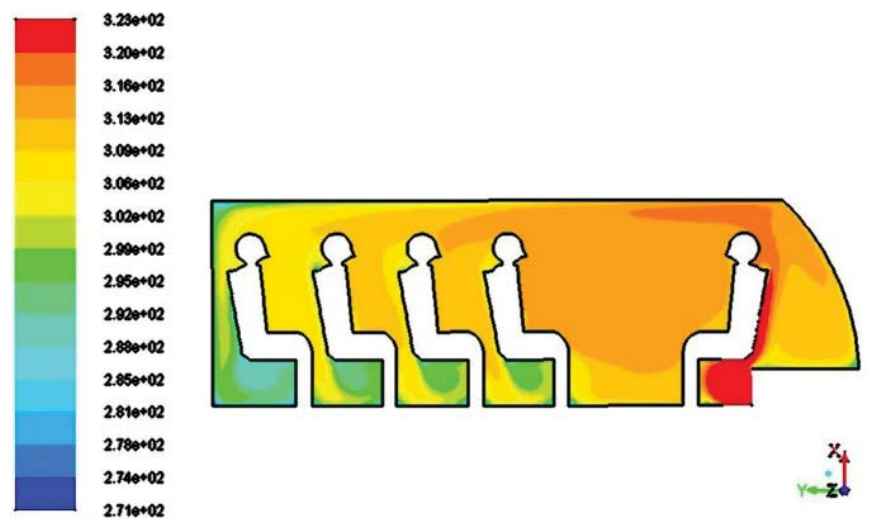

Figure 4: Distribution of absolute air temperature values in the passenger compartment of the wheeled vehicle without taking into account breathing of passengers

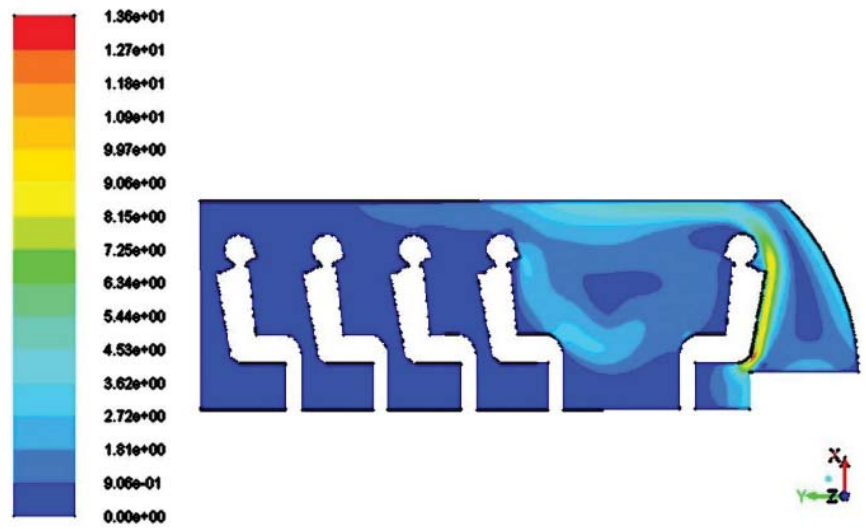

Figure 5: Distribution of air speed vector values in the passenger compartment of the wheeled vehicle without taking into account breathing of passengers

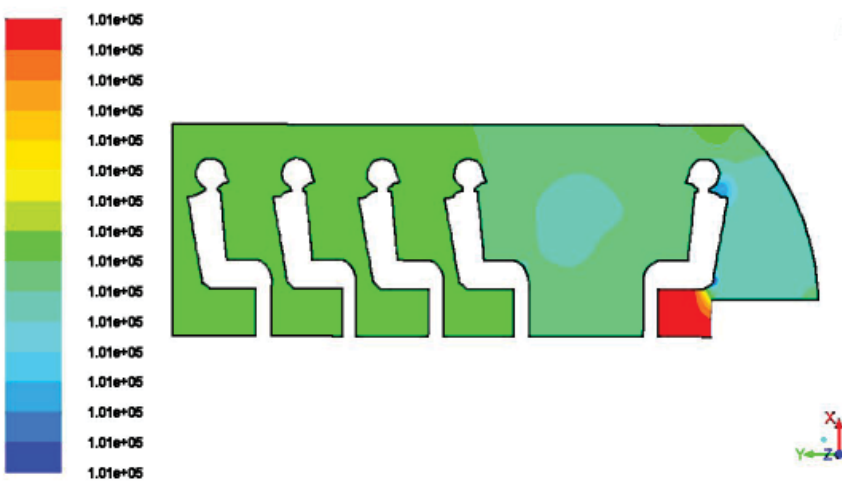

Figure 6: Distribution of absolute pressure values in the passenger compartment of the wheeled vehicle without taking into account breathing of passengers 


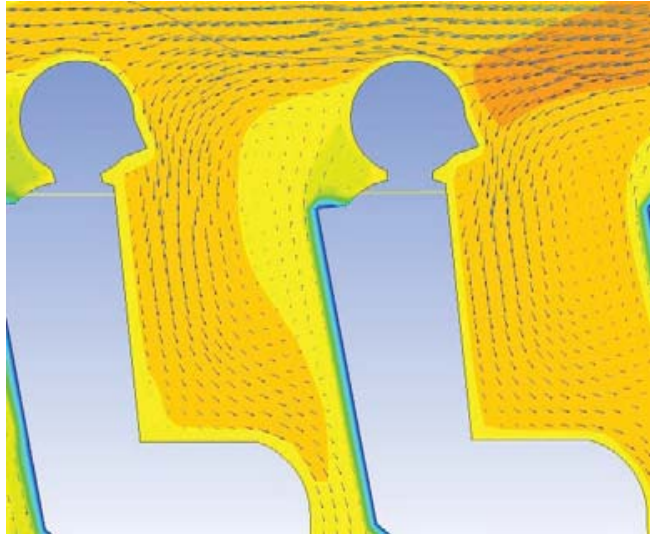

Figure 7: Fragment of airflow line vectors in the passenger's breathing zone in the compartment of the wheeled vehicle without taking into account breathing of passengers

passenger's breathing zone in the compartment of the wheeled vehicle without taking into account breathing.

Figures $8,9,10$, and 11 demonstrate the distribution of absolute air temperatures, airflow speed vector, absolute pressure and a fragment of airflow line vectors in the passenger compartment taking into account the breathing of passengers.
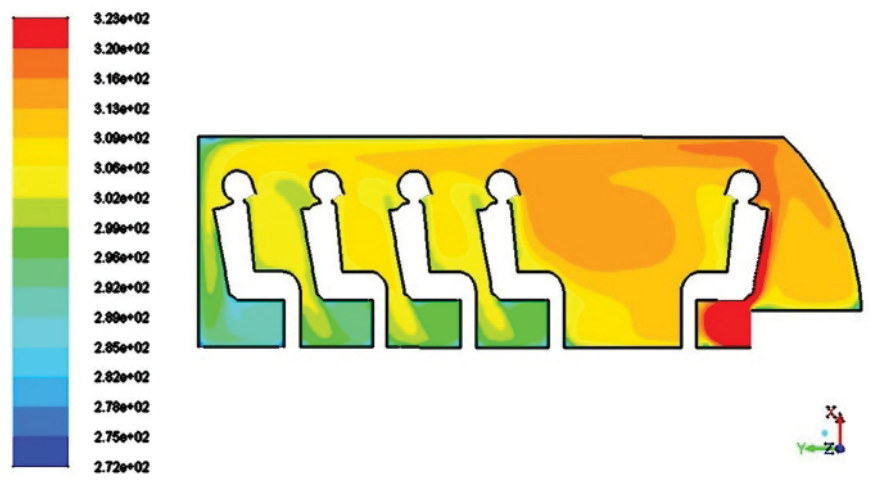

Figure 8: Distribution of absolute air temperature in the compartment of the wheeled vehicle taking into account breathing of passengers
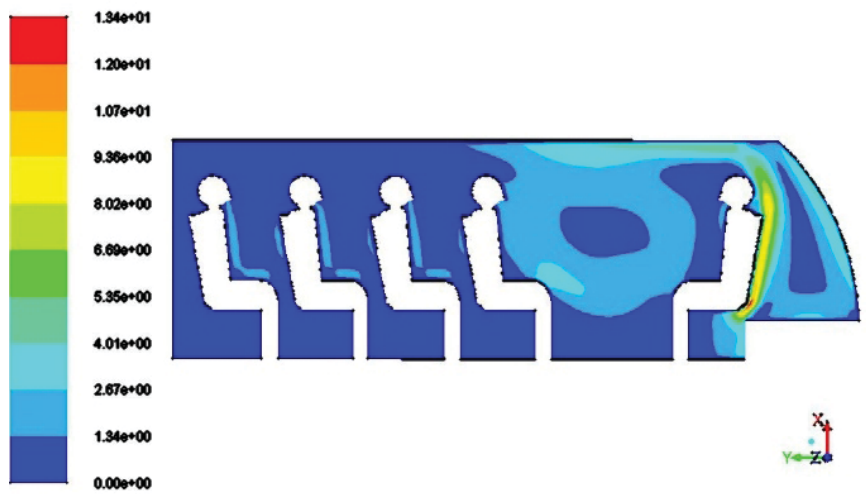

Figure 9: Distribution of airflow speed vector in the compartment of the wheeled vehicle taking into account breathing of passengers

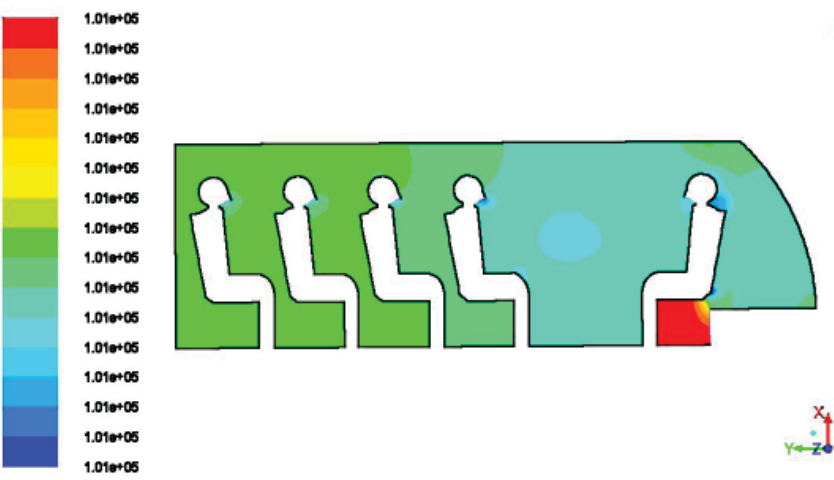

Figure 10: Distribution of absolute pressure in the compartment of the wheeled vehicle taking into account breathing of passengers

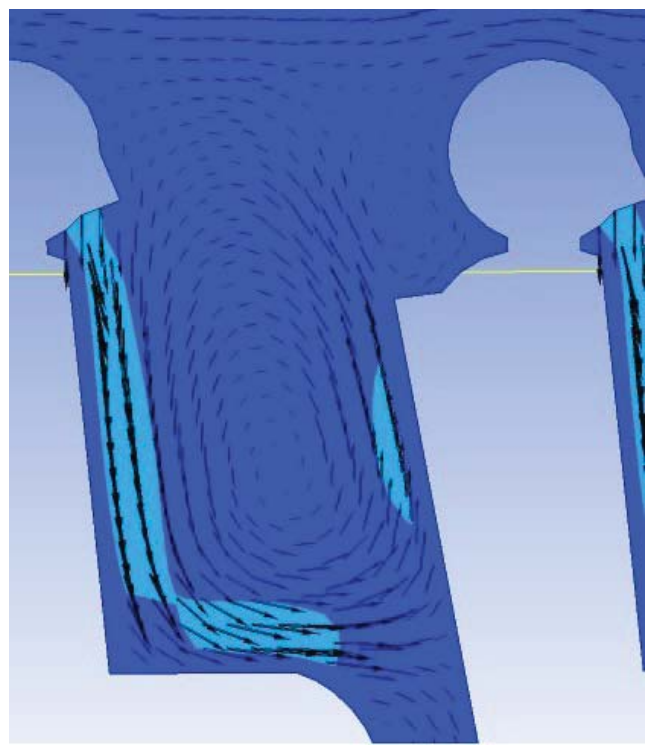

Figure 11: Fragment of airflow line vectors in the passenger's breathing zone in the compartment of the wheeled vehicle on exhalation

Figure 12 presents a fragment of airflow lines in the passenger's breathing zone on inhalation.

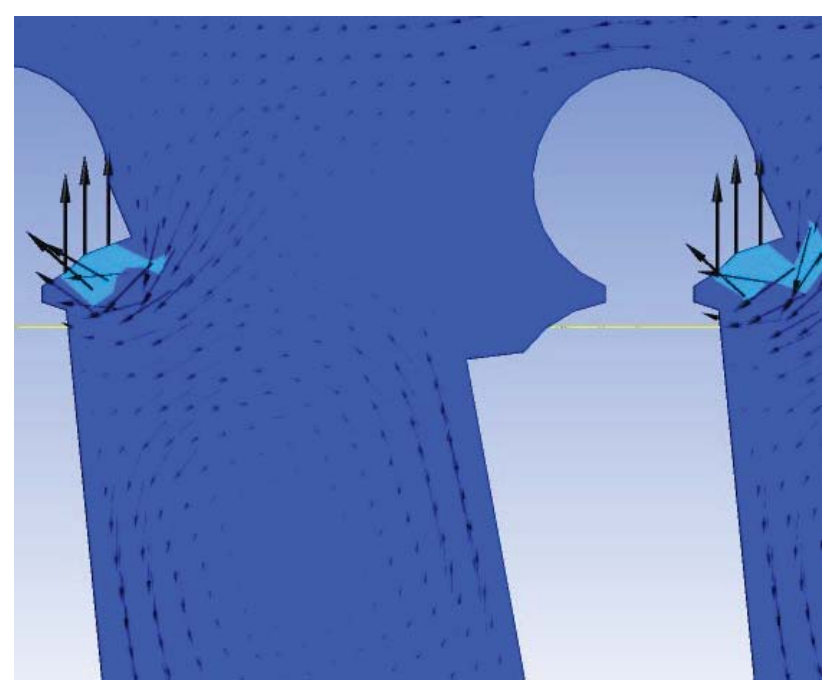

Figure 12: Fragment of airflow line vectors in the passenger's breathing zone in the compartment of the wheeled vehicle on inhalation 
Figure 13 represents the changes in temperature differences between the temperatures with and without taking into account the breathing of passengers. This figure also illustrates the temperature differences on inhalation and exhalation throughout the height of the passenger compartment in the cross-section passing through the passenger's breathing zone at the back wall of the compartment.

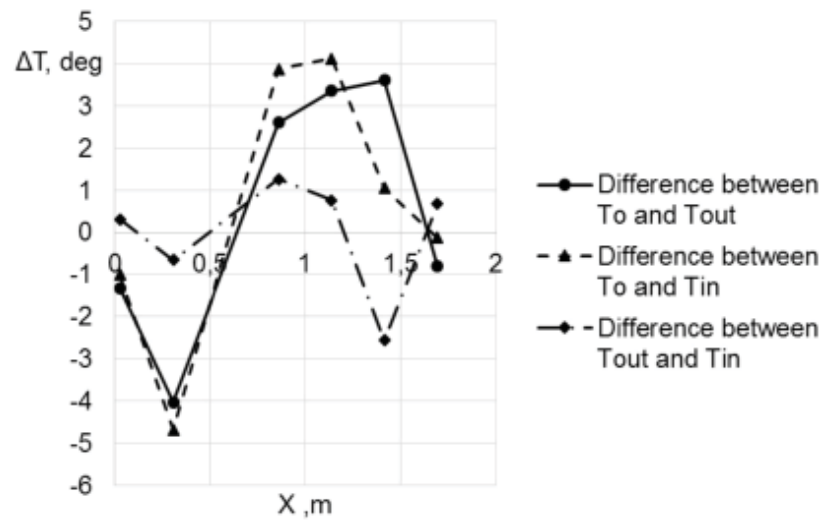

Figure 13: Changes in temperature differences throughout the height of the vehicle passenger compartment in the cross-section passing through the passenger's breathing zone at the back wall of the compartment

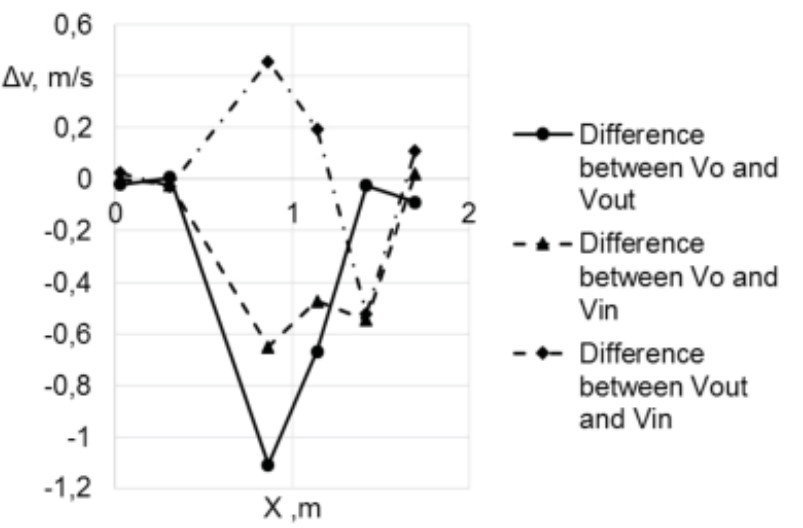

Figure 14: Changes in airflow speed differences throughout the height of the vehicle passenger compartment in the cross-section passing through the passenger's breathing zone at the back wall of the compartment

\section{DISCUSSION}

As a result of the computer simulation of the process of changing the microclimate parameters in the passenger compartment of a wheeled vehicle with the seating capacity not exceeding 22 passengers, with and without taking into account breathing, the main microclimate parameters have been obtained. Based on these parameters, it is possible to measure the degree of thermal comfort of passengers, as performed in papers [26, 28]. It has been established that the heating system under consideration is highly ineffective, because:

- The value of temperature gradient along the length of the wheeled vehicle passenger compartment is more than 8 degrees, or on the each meter the passenger compartment the air temperature reduce by mean the $2,5^{\circ} \mathrm{C}$. Consequently, a single heat source does not provide uniform heating of the entire passenger compartment space. As a result, passengers in the far side of the passenger compartment experience thermal discomfort due to the effect of lower temperatures, and passengers in the front side experience thermal discomfort due to the effect of higher temperatures, as it was also demonstrated in paper [19];

- The passenger compartment heating system is one of the key elements in the provision of thermal comfort to passengers, as was demonstrated in 2009 in paper [12]. High air temperature values will lead to higher temperatures in the breathing zone of all passengers in the passenger compartment. Maximum temperatures in the breathing zone will occur for the first passenger in the direction of the vehicle movement. Thus, the temperature of the air supplied to the passenger compartment by the heater should not be significantly higher than the temperature of the air, which is characterized by the concept of thermal comfort of passengers;

- Air speed, which is given by the heater ventilator, provides the required values by the factor of "air speed in the passenger's breathing zone", established by GOST R 53828-2010 and GOST 8802-78 along the entire length of the compartment.

Accordingly, the scheme under consideration for heating the passenger compartment does not provide real thermal comfort for passengers. To ensure the thermal comfort of each passenger of the vehicle compartment, a more complex system of microclimate parameters regulation is needed, as is proven in papers [6, 27, 33].

From the comparison of Figures 4 and 8 , it follows that the effect of passengers' breathing in the considered design of the vehicle does not have a significant impact on the temperature distribution in the compartment space, which can be caused by the fact that the difference between the initial temperature of exhaled air and body temperature was not great and was $1^{\circ} \mathrm{C}$. In this case, the effect of inhaled and exhaled air has an impact on the overall picture of the movement of air masses in the passenger compartment space, which is manifested in the reduction of time for heating the compartment air environment.

The effect of the external breathing process has a significant impact on the characteristics of the passenger's breathing zone (Figures 11 and 12). This fact is essential in the context of the distribution of temperature values in the space of the compartment and the direct impact of other factors usually not evaluated in solving various problems of thermal comfort in the compartment of a wheeled vehicle, according to papers [41, 42, 43, 44]. Inhalation and exhalation determine gas flow convective 
zones. Thus, it follows from Figure 12 that in the zone located at the level of the passenger's head there is a mixing and formation of a mixture of exhaled gas and heated by the heater air flow, which the passenger then inhales, and exhalation (Figure 11) leads to an intensification of the main air flow, moving along the cabin, directly into the breathing zone. Therefore, it is necessary to consider the dynamic pattern of the gas composition of the atmosphere in the wheeled vehicle passenger compartment and the impact of this process on thermal comfort.

The comparative analysis of the obtained results in considered cross-section indicates that the maximum difference of air temperatures on inhalation and exhalation (Figure 13) occurs at the upper part of a head and reaches $3^{\circ} \mathrm{C}$. The zone of maximum differences of temperatures throughout the height is about $0.75 \mathrm{~m}$. As for the differences between the temperatures with and without taking into account the external breathing, the difference between exhalation and inhalation with respect to the results in the absence of breathing is less than $1^{\circ} \mathrm{C}$, and their maximums take place in the lower part of the passenger compartment. Similar trends result from the diagram in Figure 14. The maximum difference between the air flow speeds on exhalation and without breathing, which reaches $1.2 \mathrm{~m} / \mathrm{s}$, is observed directly within the lower part of the passenger's face.

As can be seen from the above, the line of the following researches related to the effect of the passenger's external breathing should take into account the change of gas composition, as well as be carried out on spatial models with consideration of heterogeneity of the process of external breathing of the passenger group.

\section{CONCLUSION}

The updated computer-based model of the system "passenger - vehicle passenger compartment" has been implemented taking into account the process of passenger's external breathing of the wheeled vehicle of M3 category with the seating capacity not exceeding 22 passengers. Qualitative and quantitative characteristics of the microclimate in the passenger compartment, taking into account the external breathing process, have been obtained. The need for implementation of more complex heating systems, excluding the use of one heater, has been demonstrated. At the same time, their characteristics should have less extreme values in terms of temperature and speed of air at the outlet. The necessity to investigate the impact of gas composition change during breathing on microclimate parameters in the passenger compartment has been substantiated.

\section{REFERENCES}

1. Berestneva, O. G., Zharkova, O. S., Shevelev, G. E., \& Urazaev, A. M. (2015). Methods for analysis of adaptation processes in on-off work pattern of oilmen's labor. Modern Problems of Science and Education, 4, 212-218.
2. Cui, W., Cao, G., Park, J., Ouyang, Q., \& Zhu, Y. (2013). Influence of indoor air temperature on human thermal comfort, motivation and performance. Building and Environment, 68, 114-122. doi: 10.1016/j. buildenv.2013.06.012

3. Croitoru, C., et al. (2011). Numerical and experimental modeling of airflow and heat transfer of a human body. Roomvent 2011.

4. Nielsen, P. (2007). Analysis and Design of Room Air Distribution Systems. HVAC\&R Research, 13, 987997. doi: 10.1080/10789669.2007.10391466

5. Yang, C., Yang, X., \& Zhao, B. (2015). The ventilation needed to control thermal plume and particle dispersion from manikins in a unidirectional ventilated protective isolation room. Building Simulation, 8, 551-565. doi: 10.1007/s12273-014-0227-6

6. Schmeling, D., \& Bosbach, J. (2017). On the influence of sensible heat release on displacement ventilation in a train compartment. Building and Environment, 125, 248-260. doi: 10.1016/j.buildenv.2017.08.039

7. Aliahmadipour, M., \& Abdolzadeh, M., \& Lari, K. (2017). Air flow simulation of HVAC system in compartment of a passenger coach. Applied Thermal Engineering, 123, 973-990. doi: 10.1016/j.applthermaleng.2017.05.086

8. Bosbach, J., Lange, S., Dehne, T., Lauenroth, G., Hesselbach, F., \& Allzeit, M. (2013). Alternative Ventilation Concepts for Aircraft Cabins. CEAS Aeronautical Journal, 4, 301-313. doi: 10.1007/s13272-0130074-z

9. Canbolat, A., Turkan, B., Etemoglu, A., \& Can, M. (2016). Numerical investigation into thermal comfort conditions in a midibus. The Journal of MacroTrends in Applied Science, 4, 13-23.

10. Ivanescu, M., Neacsu, C. A., \& Tabacu, I. (2010). Studies of the Thermal Comfort Inside of the Passenger Compartment Using the Numerical Simulation. International Congress Motor Vehicles \& Motors 2010.

11. Mao, Y., \& Wang, J., \& Li, J.-M. (2018). Experimental and numerical study of air flow and temperature variations in an electric vehicle cabin during cooling and heating. Applied Thermal Engineering, 137, 356367. doi: 10.1016/j.applthermaleng.2018.03.099

12. Zhang, H., Dai, L., Xu, G., Li, Y., Chen, W., \& Tao, W.-Q. (2009). Studies of air-flow and temperature fields inside a passenger compartment for improving thermal comfort and saving energy. Part I: Test/ numerical model and validation. Applied Thermal Engineering, 29, 2022-2027. doi: 0.1016/j.applthermaleng.2008.10.005

13. Schmeling, D., \& Bosbach, J. (2019). Influence of shape and heat release of thermal passenger manikins on the performance of displacement ventilation in a train compartment. Indoor and Built Environment. doi: 10.1177/1420326X19856673 
14. Dong, Z., Zhou, B., Li, F., Wang, Y., Lin, X., \& Wu, $X$. (2017). Investigation of Thermal Plume around a Simulated Standing Operator in an Operating Room. Procedia Engineering, 205, 1940-1945. doi: 10.1016/j.proeng.2017.10.053

15. Unal, S. (2017). An Experimental Study on a Bus Air Conditioner to Determine its Conformity to Design and Comfort Conditions. Journal of Thermal Engineering, 3, 1089-1101. doi: 10.18186/thermal.277288

16. Zhou, X., Lai, D., \& Chen, Q. (2018). Experimental investigation of thermal comfort in a passenger car under driving conditions. Building and Environment, 149, 109-119. doi: 10.1016/j.buildenv.2018.12.022

17. Paul Alexandru, D., Nastase, I., Bode, F., Croitoru, C., Angel, D., \& Meslem, A. (2019). Evaluation of the thermal comfort for its occupants inside a vehicle during summer. IOP Conference Series: Materials Science and Engineering, 595, 012027. doi: 10.1088/1757-899X/595/1/012027

18. Khaiwal, R., Agarwal, N., \& Mor, S. (2020). Assessment of thermal comfort parameters in various car models and mitigation strategies for extreme heathealth risks in the tropical climate. Journal of Environmental Management, 267, 110655. doi: 10.1016/j. jenvman.2020.110655

19. Qi, C., Helian, Y., Liu, J., \& Zhang, L. (2017). Experiment Study on the Thermal Comfort inside a Car Passenger Compartment. Procedia Engineering, 205, 3607-3614. doi: 10.1016/j.proeng.2017.10.211

20. He, Y., Yang, J., Ling, J., Du, Y., \& Zhang, Z. (2020). Predictive modeling for overall thermal sensation of vehicle occupants based on local thermal sensation when warming up. Proceedings of the Institution of Mechanical Engineers, Part D: Journal of Automobile Engineering, 234(8), 2127-2134. doi: 10.1177/0954407020902564

21. Lange, P., Schmeling, D., Hoermann, H., \& Volkmann, A. (2019). Comparison of local equivalent temperatures and subjective thermal comfort ratings with regard to passenger comfort in a train compartment. IOP Conference Series: Materials Science and Engineering, 609, 032042. doi: 10.1088/1757899X/609/3/032042

22. Foda, E., Almesri, I., Awbi, H. B., \& Siren, K. (2011). Models of human thermoregulation and the prediction of local and overall thermal sensations. Building and Environment, 46, 2023-2032. doi: 10.1016/j. buildenv.2011.04.010

23. Huizenga, C., Hui, Z., \& Arens, E. (2001). A model of human physiology and comfort for assessing complex thermal environments. Building and Environment, 36, 691-699.

24. Foda, E., \& Siren, K. (2011). A new approach using the pierce two-node model for different body parts. International Journal of Biometeorology, 55, 519-532.
25. Alahmer, A., Abdelhamid, M., \& Omar, M. (2012). Design for thermal sensation and comfort states in vehicles cabins. Applied Thermal Engineering, 36, 126140. doi: 10.1016/j.applthermaleng.2011.11.056

26. Paul Alexandru, D., Vartires, A., \& Angel, D. (2016). An Overview of Current Methods for Thermal Comfort Assessment in Vehicle Cabin. Energy Procedia, 85, 162-169. doi: 10.1016/j.egypro.2015.12.322

27. Yang, C.-J., Yang, T.-C., Chen, P.-T., \& Huang, K.D. (2019). An Innovative Design of Regional Air Conditioning to Increase Automobile Cabin Energy Efficiency. Energies, 12, 2352.

28. Croitoru, C., Nastase, I., Bode, F., Meslem, A., \& Dogeanu, A. (2015). Thermal comfort models for indoor spaces and vehicles-Current capabilities and future perspectives. Renewable and Sustainable Energy Reviews, 44, 304-318.

29. Paul Alexandru, D., Bode, F., Nastase, I., \& Meslem, A. (2018). CFD simulation of a cabin thermal environment with and without human body - thermal comfort evaluation. E3S Web of Conferences, 32, 01018. doi: 10.1051/e3sconf/20183201018

30. Kristanto, D., \& Leephakpreeda, T. (2017). Sensitivity analysis of energy conversion for effective energy consumption, thermal comfort, and air quality within car cabin. Energy Procedia, 138, 552-557.

31. Khatoon, S., \& Kim, M.H. (2020). Thermal Comfort in the Passenger Compartment Using a 3-D Numerical Analysis and Comparison with Fanger's Comfort Models. Energies, 13, 690. doi: 10.3390/ en13030690

32. Marshall, G.J., Mahony, C.P., Rhodes, M.J., Daniewicz, S.R., Thompson, S.M. (2019). Thermal Management of Vehicle Cabins, External Surfaces, and Onboard Electronics: An Overview. Engineering, 5(5), 954-969.

33. Oh, M., Ahn, J., Kim, D., Jang, D., \& Kim, Y. (2014). Thermal comfort and energy saving in a vehicle compartment using a localized air-conditioning system. Applied Energy, 133, 14-21. doi: 10.1016/j.apenergy.2014.07.089

34. Li, J., Cao, X., Liu, J., Mohanarangam, K., \& Yang, W. (2018). PIV measurement of human thermal convection flow in a simplified vehicle cabin. Building and Environment, 144, 305-315. doi: 10.1016/j. buildenv.2018.08.031

35. Chen, Q. (1995). Comparison of different k- $\varepsilon$ models for indoor air flow computations. Numerical Heat Transfer, Part B: Fundamentals, 28, 353-369.

36. Chen, Q., Zhang, Z., \& Zuo, W. (2007). Computational fluid dynamics for indoor environment modeling: Past, present, and future. IAQVEC 2007 Proceedings of the 6th International Conference on Indoor Air Quality, Ventilation and Energy Conservation in Buildings: Sustainable Built Environment, 1-9. 
37. Ansys. (2012). ANSYS/FLUENT User's Manual. Release Version 14.5. https://www.ansys.com

38. Warey, A., Kaushik, S., Khalighi, B., Cruse, M., \& Venkatesan, G. (2020). Data-driven prediction of vehicle cabin thermal comfort: using machine learning and high-fidelity simulation results. International Journal of Heat and Mass Transfer, 148, 119083.

39. Simion, M., Socaciu, L., \& Unguresan, P. (2016). Factors which influence the thermal comfort inside of vehicles. Energy Procedia, 85, 472-480.

40. Almeida, M., Paula Xavier, A., Michaloski, A., \& Luiz Soares, A. (2020). Thermal Comfort in Bus Cabins: A Review of Parameters and Numerical Investigation. In: Arezes P., Santos Baptista, J., Barroso, M. P., Carneiro P., Cordeiro, P., Costa, N., Melo, R.B., Sergio Miguel, A., \& Perestrelo, G. (eds.) Occupational and Environmental Safety and Health II. Studies in Systems, Decision and Control, vol. 277. Springer, Cham, 499-506. doi: 10.1007/978-3-030-41486-354

41. Jung, H. (2013). Modeling CO2 Concentrations in Vehicle Cabin. SAE 2013 World Congress \& Exhibition. doi: 10.4271/2013-01-1497

42. Aleshkov, D.S., \& Bedrina, E.A. (2015). Physical and biological impact factors on the formation of small groups. Proceedings of the International Scientific and Practical Conference "Science of the XXI Century: The Experience of the Past - a Look into the Future", 456-460.

43. Sun, X., He, J., \& Yang, X. (2017). Human breath as a source of VOCs in the built environment, Part I: A method for sampling and detection species. Building and Environment, 125, 565-573. doi: 10.1016/j. buildenv.2017.06.038
44. Bivolarova, M., Kierat, W., Zavrl, E., Zbigniew, P., \& Melikov, A. (2017). Effect of airflow interaction in the breathing zone on exposure to bio-effluents. Building and Environment, 125, 216-226. doi: 10.1016/j. buildenv.2017.08.043

45. Vianello, A., Jensen, R., Liu, L., \& Vollertsen, J. (2019). Simulating human exposure to indoor airborne microplastics using a Breathing Thermal Manikin. Scientific Reports, 9, 8670. doi: 10.1038/ s41598-019-45054-w

46. Marshall, G.J., Mahony, C.P., Rhodes, M.J., Daniewicz, S.R., Tsolas, N., \& Thompson, S.M. (2019). Thermal Management of Vehicle Cabins, External Surfaces, and Onboard Electronics: An Overview. Engineering, 5(5), 954-969.

47. Trusov, P.V., Zaitseva, N.V., Zinker, M.Yu., \& Babushkina, A.V. (2018). Simulation of the dusty air flow in the respiratory tract. Russian Journal of Biomechanics, 22(3), 301-314.

48. Rim, D., \& Novoselac, A. (2009). Transport of particulate and gaseous pollutants in the vicinity of a human body. Building and Environment, 44, 18401849. doi: 10.1016/j.buildenv.2008.12.009

49. Potekhina, Y.P., \& Golovanova, M.V. (2010). Causes of changes in the body's local temperature. Medical Almanac, 2(11), 297-298.

50. Benderskiy, B.Ya., \& Petrov, R.A. (2017). Investigation of the spatial processes of the bus passenger compartment heating. Truck, 6, 3-8. 